\title{
La experiencia escocesa en los referenda de devolución y secesión The Scottish experience of devolution and secession referenda
}

\author{
Malcolm Harvey \\ University of Aberdeen \\ malcolm.harvey@abdn.ac.uk
}

Recibido / received: 04/08/2017

Aceptado / accepted: 18/08/2017

DOI: https://doi.org/10.20318/eunomia.2017.3805

\section{Resumen}

Consultar e involucrar a la población se ha vuelto habitual en los últimos años. El Reino Unido, que no cuenta con una constitución codificada, ha utilizado el referéndum para decidir sobre diversas cuestiones constitucionales, siendo la más reciente la consulta sobre la permanencia del Reino Unido en la Unión Europea en junio de 2016. Este artículo explora la experiencia escocesa de referenda, examinando el fallido referéndum de devolución de 1979, su repetición exitosa en 1997, y el referéndum de independencia de 2014, en el que los escoceses, de forma aparentemente decisiva, decidieron quedarse en el Reino Unido. Este artículo argumenta que, aunque en cada ocasión fueron las consideraciones políticas, más que los principios, los que llevaron al uso del referéndum, defensores de la democracia directa y activistas y defensores de casos similares pueden aprender algunas lecciones de todas ellas.

\section{Palabras clave}

Escocia, Referenda, Devolución, Independencia.

\begin{abstract}
Consulting and engaging with the public has become vogue in recent years. The United Kingdom, without a codified constitution, has utilised the referendum to decide upon constitutional issues, with the vote to leave the European Union in June 2016 the most recent of these. This article explores the Scottish experience of referendums, examining the failed devolution referendum of 1979, the reversal of this decision in 1997, and the independence referendum of 2014, in which Scots, apparently decisively, voted to remain in the UK. This article argues that, though on each occasion political considerations rather than principle led to the use of referendums, there are lessons to be learned from each, both for proponents of direct democracy and for campaigners and activists in similar cases.
\end{abstract}

\footnotetext{
* Nota del traductor: de aquí en adelante, se utilizará el término "devolución" como traducción más próxima al inglés "devolution". Este concepto debe ser entendido como la "devolución" del Poder Legislativo al nuevo ente independiente, es decir, la creación en él de una cámara legislativa propia.

** Traducción de Jorge San Vicente Feduchi.
} 


\author{
Keywords \\ Scotland, Referendums, Devolution, Independence.
}

SUMARIO. 1. Introducción. 2. Referenda y el proceso democrático. 3. El referéndum de devolución de 1979. 4. El referéndum de devolución de 1997. 5. Control de los tiempos y cooperación: ¿cuestiones clave? 6. El proceso hacia el referéndum de 2014. 7. El contexto cambiante.

8. Conclusión.

\title{
1. Introducción
}

En el Reino Unido (al contrario que, por ejemplo, en la República de Irlanda), no es necesario un referéndum para alterar los acuerdos de Gobierno o las circunstancias constitucionales. A pesar de que el Reino Unido no tiene una constitución única y codificada, decir que no tiene una "constitución" escrita es impreciso: la Constitución británica está escrita en varios documentos, los cuales incluyen la Magna Carta, ciertas las leyes del Parlamento o la obra Erskine May: Parliamentary Practices, así como en la costumbre y en precedentes. Con tal fin, el Gobierno de turno puede utilizar los referenda cuando así lo vea necesario y políticamente prudente. Por ello su uso no ha sido especialmente escrupuloso, pero han tenido un propósito claro: asegurarse de que los cambios constitucionales propuestos tienen el apoyo del público antes a su implementación. Pero en ocasiones - como pasó recientemente, en el referéndum sobre el brexit-, los votantes han acabado rechazando la opción preferida del Gobierno; y cuando esto ocurre, éste acepta el resultado como si la consulta fuera vinculante.

En tres ocasiones durante los últimos 40 años, el electorado escocés ha sido consultado sobre el nivel de autonomía que debería ser otorgado a Escocia. En 1979, Escocia votó, por poco margen, a favor de un Parlamento escocés, aunque el apoyo no logró el umbral de participación requerido y la legislación fue por tanto derogada. En 1997, un Parlamento escocés más fuerte (con poderes para manejar asuntos fiscales) fue apoyado ampliamente por el electorado y finalmente establecido en 1999. Y en 2014, el Partido Nacional Escocés (SNP, en sus siglas en inglés), que había conseguido la mayoría en dicho Parlamento, acordó con el Gobierno británico la celebración de un referéndum que permitiese al electorado votar sobre su misma raison d'être: la independencia. La propuesta fue rechazada con un 55 por ciento del voto en contra. En cada ocasión, el referéndum fue utilizado para involucrar a la ciudadanía en el proceso, por lo que podemos aprender lecciones de cada una de esas experiencias.

El presente artículo examina en detalle estos tres referenda, considerando los procesos que cada uno siguió, cómo se involucraron los actores principales y el impacto de dos factores comunes a cada caso: el momento en el que se llevó a cabo el referéndum y la coordinación y cooperación de las partes para conseguir su resultado preferido. Con tal fin, el artículo destaca el papel del referéndum en las democracias representativas, y específicamente en el Reino Unido, argumentando que deben ser utilizados tan solo en circunstancias particulares - circunstancias que el Reino Unido ha mantenido desde el primer uso de un referéndum en 1973-. En segundo lugar, el artículo estudia los procesos que se llevaron a cabo en los tres referenda relativos a la autonomía de Escocia (en 1979, 1997 y 2014), comparando 
las campañas, los tiempos y la implicación de los votantes en cada uno de ellos. Finalmente, el artículo destaca un cambio en el contexto para el uso de referenda y otros mecanismos de participación ciudadana en el Reino Unido, especialmente desde el cambio de siglo, argumentando que, aunque la población parece más dispuesta a participar en el proceso político de un referéndum que en el de unas elecciones, la experiencia reciente del brexit ha alterado, potencialmente, la opinión pública de cuándo deben celebrarse las consultas populares.

Aunque el autor esté ampliamente a favor del principio de participación ciudadana como un componente positivo de los referenda, el artículo defiende que, de varias maneras, el referéndum ha sido utilizado cínica y estratégicamente como una herramienta partidista. Ante la expectativa de futuros referenda constitucionales en el horizonte - la posibilidad de que se celebre un segundo referéndum de independencia en Escocia o los esfuerzos continuados de Cataluña para hacer lo propio por primera vez son solo dos de estos ejemplos-, podemos extraer algunas lecciones de la experiencia escocesa. En particular, el papel del Gobierno central para legitimar el referéndum -así como la alta participación en el referéndum sobre la independencia en 2014- es un claro beneficio para el proceso democrático.

\section{Referenda y el proceso democrático}

El referéndum es el ejemplo más claro de democracia directa utilizado en las democracias representativas contemporáneas, por lo que su uso se ha vuelto común (Butler y Ranney, 1994). Para algunos, el aumento en su uso se explica por el papel negativo del pueblo en las democracias representativas; es decir, que el poder del pueblo se limita a seleccionar y deseleccionar a sus representantes de preferencia en elecciones (Bogdanor, 1994). Para otros, es una cuestión de incrementar la legitimidad de una medida particular; si la gente vota por ello, parece tener más legitimidad (Papadopoulous, 2001). Para Qvortrup, los referenda son "un suplemento de la democracia indirecta", dando a los ciudadanos el voto decisivo y la oportunidad de llevar a la democracia más cerca del "ideal de gobierno por discusión" que a través de votos dispersos que responden a una línea de partido de las democracias representativas contemporáneas (Qvortrup, 2005). Sin embargo, Chambers argumenta que la polarización del debate en los referenda y la inevitabilidad de resultados mayoritarios en realidad "perjudica la deliberación y, en su camino, debilita la legitimidad de los resultados". En efecto, ello conlleva a considerar la votación en un referéndum como "final" y a tratar al propio referéndum como un "juego de suma cero" (Chambers, 2001: 240-245). La crítica de LeDuc's (2003) va más allá, al subrayar que los referenda son habitualmente susceptibles a "información insuficiente, preguntas confusas o argumentaciones contradictorias en cuanto a las consecuencias de la votación". Tierney (2012) destaca que los referenda en contextos de democracia representativa son problemáticos, potencialmente anti-democráticos y pueden no ser el método más apropiado de involucrar directamente a la población en discusiones políticas $(\mathrm{y}$, especialmente, constitucionales). El más famoso partidario del referéndum en el Reino Unido, A.V. Dicey, consideraba al referéndum una respuesta a lo que él veía como el problema de que una pequeña mayoría de la Cámara de los Comunes pudiera cambiar la Constitución sin que el pueblo tuviera ninguna influencia en la decisión (Qvortrup, 2005: 47). Desde su punto de vista, el referéndum era un "mecanismo conservador" dada su propuesta de utilizar los referenda para limitar la capacidad del Parlamento de alterar radicalmente la Constitución sin tener necesariamente el apoyo de la ciudadanía (Constitution Unit, 1996: 19). Bogdanor argumenta que Dicey tiene y no tiene razón: tiene razón en cuanto a que, en lo que se refiere a cuestiones constitucionales, la opinión del pueblo debería contar más que la del Parlamento; 
pero no la tiene al decir que el referéndum solo podría utilizarse en un número pequeño de cuestiones constitucionales (Bogdanor, 1996: xv-xix).

En el Reino Unido, los referenda tienen una naturaleza ad hoc y consultiva: ad hoc porque no hay un requerimiento constitucional de que algunos asuntos se decidan por referéndum, por lo que los Gobiernos pueden decidir recurrir a ellos por varias razones; y consultiva porque el principio de soberanía parlamentaria supone que, sea cual sea el resultado, el Parlamento británico conserva la autoridad de no estar comprometido a este y de actuar de la manera que considere apropiada. $Y$ dado que los referenda en el Reino Unido no están estipulados por ninguna legislación formal -y que la justificación constitucional para su celebración difiere en cada caso, dificultando su determinación por precedente- la conveniencia política se vuelve una motivación relevante al tomar la decisión de convocarlos (Balsom, 1996: 221). Esto da el control de los referenda a los Gobiernos británicos de varias maneras. Pueden decidir sobre las cuestiones que se discutirán en un referéndum, cuándo se celebrará y cuál será la pregunta. En resumen, controlan la agenda del referéndum y su puesta en marcha (Setäla, 2006: 709). Generalmente, el partido gobernante solo se decidiría a convocar un referéndum si considera que ganará (Le Duc, 2002). Sin embargo, en ocasiones, para el electorado, el referéndum no es un procedimiento aislado sobre una cuestión en particular, sino que la votación puede convertirse en un juicio de la labor del Gobierno. Esto también influirá en la decisión de un Gobierno de convocar una consulta popular.

La Cámara de los Lores solicitó a su Comité Especial sobre la Constitución la investigación del "papel de los referenda en la experiencia constitucional británica". El informe estudió una serie de fuentes a favor de continuar, expandir o formalizar el uso de referenda en el Reino Unido. Entre los argumentos a favor se encontraban: resolver un problema; incrementar la participación ciudadana; promocionar la educación democrática; salvaguardar al Parlamento o al Gobierno ante decisiones polémicas; el hecho de que, cuando los votantes dejan clara su posición en un referéndum, dicha posición es difícil de revertirse; y que el referéndum es un complemento de la democracia representativa tal y como es practicada en el Reino Unido (House of Lords, 2010). En su contra, consideraron también argumentos como que los referenda eran simples mecanismos tácticos; que las campañas estaban dominadas por las élites; que tenían un impacto negativo sobre las minorías; que suponían un obstáculo para el progreso; que no resuelven la cuestión; que tienden a divergir de la pregunta; que son caros; y que, de hecho, debilitan la democracia representativa. Concluyeron que, mientras compartían las críticas a la naturaleza ad hoc de los referenda -específicamente, a su uso como mecanismo táctico-, los referenda tenían su papel en el Reino Unido; concretamente, resultaban apropiados cuando se trataban "asuntos constitucionales fundamentales", tal y como el cambio del sistema electoral de la Cámara de los Comunes o cuestiones de secesión nacional de la Unión.

Qvortrup establece cinco tipos distintos de referéndum: transferencias de soberanía, cuestiones constitucionales, cuestiones económicas, cuestiones morales y asuntos varios como la adopción, la energía nuclear o la conducción por la derecha (Qvortrup 2005: 63). Los referenda de devolución previos entrarían claramente en la categoría de cuestiones constitucionales, aunque el referéndum propuesto por el Gobierno del SNP probablemente se solaparía con la categoría de transferencias de soberanía dado que su contenido afecta a aspectos de ambas. Asimismo, la propuesta de referéndum conllevó fines políticos específicos para ayudar a resolver los dilemas del partido en cuanto a políticas, responsabilidades y votos (Müller y Strøm, 1999). Ayudó al SNP a abstraerse de la independencia en las elecciones escocesas y aumentó su capacidad de obtener el Gobierno; los votantes 
podían apoyar al SNP, por ejemplo, en base a sus políticas, sabiendo que ese apoyo no significaba una independencia inminente, sino que votaban a favor de un referéndum no necesariamente inmediato. En este sentido, el referéndum independentista del SNP está diseñado pensando en sus votantes y sus detractores y tiene similitudes con los referenda de devolución previos. Los referenda de devolución de 1979 y 1997 fueron promovidos por la oposición (Qvortrup 2005: 106): la iniciativa de 1979 vino de la oposición a la devolución mientras que el de 1997 fue diseñado para desarmar una campaña conservadora contra los poderes relativos al Impuesto sobre la Renta del Parlamento escocés (los poderes de variación de impuestos, como fueron descritos en la papeleta). Sin embargo, como se discute más abajo, las cuestiones relacionadas con el uso del referéndum en ambos casos eran heterogéneas y complejas.

Existen otras dos cuestiones a destacar sobre el uso de referenda en Reino Unido. En primer lugar, dada la ausencia de una constitución codificada y la prevalencia de la soberanía parlamentaria en la cultura jurídica británica, merece la pena recordar que los referenda son meramente consultivos, no constitucionales o vinculantes. El Reino Unido no tiene normas constitucionales ni disposiciones para los referenda, por lo que existe un elemento ad hoc en ellos, aunque actualmente existe cierta consistencia en su organización y conducta debido al trabajo regulatorio de la Comisión Electoral. En el contexto del Reino Unido como monarquía constitucional, el Gobierno no tiene la obligación de otorgar a la ciudadanía la oportunidad de votar sobre determinadas cuestiones -el sistema de democracia representativa permite al electorado votar a un parlamentario, que votará en la Cámara de los Comunes como su representante-. Este sentimiento está tan imbuido en la tradición democrática británica que rara vez se ha recurrido a referenda; y cuando se ha hecho, estos han tenido siempre un carácter no vinculante y consultivo, manteniendo por tanto la soberanía del Parlamento británico (Bogdanor, 1996: 223). No obstante, se ha establecido un precedente en el que, cuando se legisla sobre asuntos constitucionales, el Gobierno consultará a la ciudadanía a través de un referéndum $-\mathrm{y}$ aunque estos sean teóricamente consultivos, el Gobierno ha respetado la opinión pública en cada uno de los once referenda celebrados hasta la fecha-.

Tabla 1: Referenda en el Reino Unido (1973-2016)

\begin{tabular}{|l|l|l|l|}
\hline Año & Cuestión & Área del RU & Resultado \\
\hline 1973 & $\begin{array}{l}\text { Soberanía de Irlanda del } \\
\text { Norte }\end{array}$ & Irlanda del Norte & $\begin{array}{l}\text { Irlanda del Norte se } \\
\text { mantiene en el Reino Unido }\end{array}$ \\
\hline 1975 & Entrada en la CEE & $\begin{array}{l}\text { Todo Reino } \\
\text { Unido }\end{array}$ & $\begin{array}{l}\text { Reino Unido se mantiene } \\
\text { en la CEE }\end{array}$ \\
\hline 1979 & Devolución de Escocia & Escocia & $\begin{array}{l}\text { Asamblea No (regla del } \\
40 \%)\end{array}$ \\
\hline 1979 & Devolución de Gales & Gales & Asamblea No \\
\hline 1997 & Devolución de Escocia & Escocia & $\begin{array}{l}\text { Aceptado el Parlamento } \\
\text { escocés }\end{array}$ \\
\hline 1997 & Devolución de Gales & Gales & $\begin{array}{l}\text { Aceptada la Asamblea de } \\
\text { Gales }\end{array}$ \\
\hline 1998 & Devolución de Londres & Londres & $\begin{array}{l}\text { Establecimiento de la } \\
\text { Autoridad del Gran Londres } \\
\text { y de su alcaldía }\end{array}$ \\
\hline
\end{tabular}




\begin{tabular}{|l|l|l|l|}
\hline 1998 & Acuerdo de Viernes Santo & Irlanda del Norte & Acuerdo aceptado \\
\hline 2004 & Devolución del noreste & $\begin{array}{l}\text { Noreste de } \\
\text { Inglaterra }\end{array}$ & Asamblea No \\
\hline 2011 & $\begin{array}{l}\text { Poderes de devolución de } \\
\text { Gales }\end{array}$ & Gales & $\begin{array}{l}\text { Ampliación de poderes para } \\
\text { la Asamblea de Gales }\end{array}$ \\
\hline 2011 & Voto alternativo & $\begin{array}{l}\text { Todo Reino } \\
\text { Unido }\end{array}$ & $\begin{array}{l}\text { En contra de cambios en el } \\
\text { sistema electoral }\end{array}$ \\
\hline 2014 & Independencia de Escocia & Escocia & $\begin{array}{l}\text { Escocia se mantiene en el } \\
\text { Reino Unido }\end{array}$ \\
\hline 2016 & Permanencia en la UE & Reino Unido & Reino Unido sale de la UE \\
\hline
\end{tabular}

En segundo lugar, la Constitución -en términos generales- es materia reservada, lo que significa que el Parlamento tiene los poderes para legislar en este aspecto. Esto abre dos vías para que el Parlamento escocés convoque un referéndum sobre una cuestión constitucional: o, por un lado, llega a un acuerdo con el Parlamento británico para que éste le otorgue la competencia temporal de legislar a favor de un referéndum (como ocurrió en el referéndum sobre la independencia de 2014) o, por otro lado, prosigue sin contar con la aprobación del Parlamento británico, pero con una pregunta menos directa. La segunda vía era la preferida por el Gobierno del SNP antes de alcanzar la mayoría en las elecciones al Parlamento escocés de 2011. Entonces consideraban que la Ley de Escocia (Scotland Act) no permitía un referéndum con una pregunta de Sí/No sobre la independencia, pero sí una sobre si se negociaba un acuerdo de independencia con el Gobierno del Reino Unido. La SNP había tomado esto en consideración y su intención era diseñar una pregunta que fuese "constitucional" y pudiese ser aprobada a través del proceso legislativo del Parlamento escocés (es decir, que obtuviese un certificado de validez jurídica por parte del Presidente de la Cámara, el apoyo en el Parlamento de un ministro relevante y la aprobación del secretario de estado escocés). La mayoría obtenida por el SNP y las subsecuentes negociaciones con el Gobierno del Reino Unido, que derivaron en el Acuerdo de Edimburgo, hicieron que el nuevo Gobierno escocés desestimara esa estrategia y permitiera una pregunta de Sí/No (Harvey y Lynch, 2012).

\section{El referéndum de devolución de 1979}

En los setenta, la idea de un referéndum como consulta previa al establecimiento de una asamblea nacional no entraba en los planes del Gobierno. El proyecto de ley conjunto para Escocia y Gales de 1976 —tumbado en la Cámara de los Comunes en 1977 por una moción "guillotina"- concedía el principio de referéndum a los antidevolucionistas para tratar de salvar la ley. En aquel momento, se pensaba que esta estrategia habría disminuido las opciones de que la devolución tomara efecto en Gales - donde el apoyo popular era débil- pero aumentado las opciones de establecer una asamblea escocesa, dado que los escoceses parecían estar a favor de la devolución (Drucker y Brown, 1980). Finalmente se reintrodujeron dos proyectos de ley separados para cada región a finales de 1977. El proyecto para Escocia fue entonces publicado en noviembre de 1977 e incluía la concesión del Gobierno de un referéndum postlegislativo, manteniéndose ésta invariable en los posteriores debates. Fue esta concesión la que establecería un precedente para cambios constitucionales futuros.

Sin embargo, la decisión de proceder por la vía del referéndum no fue especialmente bienintencionada. La cuestión a debate no era si los cambios constitucionales deben requerir una votación pública. El Gobierno laborista se 
enfrentaba a una clara división interna -como también había ocurrido en el debate sobre la permanencia en la Comunidad Económica Europea (CEE) en 1975- y, de nuevo, consideraron que era políticamente apropiado consultar a la ciudadanía en un referéndum (Bochel et. al. 1981: 170). Lo que estaba claro era que el derecho a votar sobre los cambios constitucionales sería limitado a aquellos a los que estos afectarían directamente; por tanto, solo los electores de Escocia y Gales serían consultados sobre las propuestas de devolución. Esto constituía también un precedente importante, pues no solo afectaba a futuros referenda de devolución (en 1997), sino que también establecía el principio bajo el que cada una de las naciones que componen el Reino Unido podría determinar autónomamente los términos de su membresía (Bogdanor, 1979: 156). Sin embargo, dada la percepción del amplio apoyo a la devolución en Escocia, el referéndum no fue considerado como una concesión lo suficientemente grande para los anti-devolucionistas del bando laborista. En enero de 1978 se aprobó por tanto una enmienda al proyecto de ley para Escocia -así como para el de Gales, donde el apoyo de los votantes parecía disminuir aún más - por la que se establecía que, para que la legislación saliese adelante, el $40 \%$ de los electores deberían apoyarla. La enmienda de Cunningham, como se denominó al umbral requerido, fue un golpe crítico para los defensores de la devolución.

La campaña en el referéndum de devolución de 1979 estuvo fuertemente condicionada por algunas consideraciones partidistas; en concreto, por el efecto del referéndum sobre el Gobierno laboralista, por las futuras elecciones generales en el Reino Unido, y por varias contiendas electorales entre el Partido Laborista y el SNP en las elecciones generales de octubre de 1974 y las subsiguientes elecciones locales. El laborismo estaba dividido en la cuestión de la devolución tanto en Westminster como en las organizaciones locales. Aun así, el partido quería atribuirse exclusivamente el mérito de una victoria del Sí. Los conservadores tenían claro su apoyo al No, pero no querían dañar sus expectativas de voto en Escocia para las elecciones generales por ser considerados como anti-escoceses. El Partido Conservador también tuvo que manejar algunas divisiones internas respecto a la devolución, pues algunos de sus parlamentarios y miembros estaban a favor de una Asamblea escocesa. EI SNP estaba definitivamente a favor del Sí en 1979, pero mantenía sospechas respecto al proceso y a la propia cuestión de la devolución puesto que estaban haciendo campaña por algo en lo que no creían —una devolución reducida-, mientras que algunos parlamentarios y activistas laboristas hacían campaña en contra de las propuestas de su Gobierno.

En términos de organización, existían diferentes grupos de campaña. En particular, el bando del Sí evidenció las amplias divisiones que levantaba el asunto de la devolución. En este lado se encontraba Yes for Scotland. A pesar de la intención de hacer de este un movimiento que reuniera a votantes de todos los partidos, la ausencia de apoyos de los laboristas y los conservadores hizo que se acabara identificando con el SNP y el disidente Partido Laborista escocés de Jim Sillars. El laborismo decidió luchar por su propia campaña, en lugar de "ensuciarnos las manos uniéndonos a cualquier grupo heterogéneo del Sí", como dijo Helen Liddell, la Secretaria General escocesa del partido (Bochel, Denver y Macartney 1981: 17). En cambio, el partido creó el Labour Movement Yes, conformado por parte del laborismo, los sindicatos y el Partido Cooperativo. El tercer grupo del bando del Sí era la Alianza por la Asamblea, cuya intención era mostrar la unidad entre partidos como alianza entre parlamentarios tories, laboristas y liberales, pero prácticamente pasó inadvertida. También existía una campaña para el Sí del Partido Conservador, con parlamentarios destacados como Alick Buchanan-Smith y Malcolm Rifkind, así como actos de campaña individuales por parte del Partido 
Liberal y el Partido Comunista. El resultado de todo esto fue una campaña por el Sí desunida, afectada por los intereses de partido.

En el bando del No estaban Scotland Says No y Labour Vote No. El primero estaba formado por conservadores y empresarios y sirvió como la organización transversal del No. Tenía fondos de considerable calado y la oportunidad de dirigir su atención a la norma del $40 \%$, no solo al voto del No. Los conservadores también llevaron a cabo su propia campaña individual, pero Scotland Says No fue el centro de atención de las actividades del partido - en parte porque distraía hasta cierto punto a los tories de la cuestión de la devolución-. De forma paralela actuaba Labour Vote No, dirigida por Brian Wilson y Tam Dalyell. Labour Vote No fue importante porque suponía que había una oposición transversal activa a la Asamblea escocesa y una organización que podía atraer al electorado laborista escocés más allá de la opción conservadora/empresarial.

\section{El referéndum de devolución de 1997}

Tras la derrota en el referéndum de devolución de 1979, se precisaba de una nueva campaña para recuperar la atención del público. Esta llegó, oportunamente, a través de la Comisión Constitucional escocesa. La Comisión emitió una serie de recomendaciones sobre el sistema electoral, la representación de las mujeres y el papel del Parlamento escocés en los contextos europeo y británico, además de la peliaguda cuestión fiscal (Scottish Constitutional Convention, 1994). Mientras que la Comisión no resolvió adecuadamente cada uno de estos problemas, al menos proporcionó un foro de discusión y una agenda para negociaciones futuras entre las partes (Lynch, 1996). La misma Convención elaboró dos documentos en 1995. El primero, "Key Proposals for Scotland's Parliament", publicado por el Comité Ejecutivo en octubre, actualizaba el documento "Towards Scotland's Parliament", de 1990, con los principios que se habían convenido recientemente (que incluían un nuevo sistema de elección de los 129 miembros que compondrían el Parlamento escocés) (Scottish Constitutional Convention, 1995a). El "Scotland's Parliament, Scotland's Right", que recogía las anteriores propuestas y sería el informe final de la Convención, fue publicado el 30 de noviembre (el Día de San Andrés) (Scottish Constitutional Convention, 1995b). Fue crucial el hecho de que en ambos casos se mantuvo el apoyo tanto de los liberaldemócratas como de los laboristas, quienes probablemente obtendrían el nuevo Gobierno. Al obtener el apoyo de ambos en sus respectivos congresos al año siguiente, la Convención hizo que la devolución fuese una promesa clave de sus manifiestos electorales en las próximas elecciones. Sin embargo, a mediados de 1996, un año antes de las elecciones, el líder laborista Tony Blair anunció que, si su partido ganaba las elecciones, la legislación de devolución sería de nuevo sometida a referenda; en plural, porque la proposición de otorgar al Parlamento escocés capacidad de decisión sobre asuntos fiscales sería también objeto de una consulta. Un examen de la opinión pública estaba de vuelta en la agenda sobre la devolución.

Naturalmente, esto sorprendió a la Convención Constitucional escocesa, y muchos de los implicados sospechaban que el anuncio de Blair no fuese más que una maniobra para frustrar los planes de la devolución. Muchos también lo tomaron como una intromisión de Londres en el proceso. George Robertson, secretario de Estado "en la sombra" de Escocia, había informado hasta una semana antes del anuncio de Blair de que no habría referéndum, mientras que el parlamentario John McAllion dimitió de su puesto como protesta por no haber sido consultado sobre el cambio de estrategia (McCrone y Lewis, 1999: 19). Se organizaron reuniones entre Tony Blair y Kenyon Wright, que aún presidía el Comité Ejecutivo de la Convención. Wright concluyó que el referéndum había sido utilizado como un mecanismo táctico 
dirigido a facilitar la aprobación de un proyecto de ley para Escocia en el Parlamento británico $-\mathrm{y}$, específicamente, para consolidar al Parlamento como parte del escenario político-. A pesar de no ser reconocido por los detractores de un referéndum, la propuesta de Blair fue, en realidad, la continuación de la estrategia de su predecesor en lo que respecta a la devolución. John Smith, en una entrevista realizada en 1981 en los días posteriores al primer referéndum de devolución, declaró que un nuevo referéndum sería "inevitable", lo que "daría al Gobierno una base sólida para seguir adelante" (McCrone y Lewis, 1999: 18-22). La opinión de Smith no era solo que el referéndum era positivo para la devolución —que, como pretendía Tony Blair, consolidaría la futura asamblea escocesa-, sino que además el precedente de la consulta de 1979 precisaba que cualquier avance hacia la devolución fuese objeto de una estrategia similar. Estas reflexiones, además del deseo de consultar a la ciudadanía y el precedente del anterior referéndum, ayudaron a dar forma a la estrategia del SNP para conseguir la independencia.

La naturaleza del anuncio, sin embargo, causó cierta consternación entre los partidos políticos escoceses, así como en la Convención Constitucional escocesa. El Comité Ejecutivo Nacional del laborismo escocés tuvo que ser convencido de apoyar la propuesta —algo que solo hizo tras preguntárselo dos veces-. Los presidentes de la Convención no estaban demasiado contentos con la decisión, que no había sido consultada de antemano, y los liberaldemócratas estaban igualmente molestos (Harvie y Jones, 1999: 173). A la Convención le preocupaba que la labor de informar, educar y concienciar a la ciudadanía escocesa - una labor con la que se había comprometido- no se había llevado a cabo, y presentaron pruebas de la falta de conexión con el pueblo durante el proceso (Wright, 1997: 230). Sin embargo, de nuevo se tendieron puentes entre las partes y la Convención su unió a la propuesta de devolución. Dos semanas después de la victoria en 1997 del Partido Laborista en las elecciones generales - con un margen aplastante-, el proyecto de ley para el referéndum fue publicado y este fue convocado para el 11 de septiembre de 1997 (McCrone y Lewis, 1999: 24). Mientras que, por un lado, la Convención reconocía que existía una clara demanda a favor de la devolución, como evidenciaban las encuestas de opinión en las semanas previas y posteriores a las elecciones generales, también reconocían que esta no valdría de nada si la campaña estaba tan desunida como en 1979. Esto significaba que debían tender lazos con el SNP, que había permanecido fuera del proceso de la Convención, puesto que tomaban a esta como un medio para disminuir las posibilidades de independencia. Conseguir el apoyo del SNP era un objetivo clave, para lo cual se hicieron subsecuentes movimientos en el verano de 1997 (McLean, 2005: 164). El propio SNP quería esperar a ver cómo sería el Libro Blanco de los laboristas (eventualmente publicado como Scotland's Parliament [Cm. 3658]) antes de comprometerse a la campaña a favor de la devolución. El antiguo líder de la SNP Gordon Wilson estaba vehementemente en contra de apoyar la campaña, denominándola como la "ciénaga de la devolución", pero el Consejo Nacional del partido votó ampliamente a favor del doble Sí (ambas cuestiones -la de la devolución y la de materia fiscal- habían sido combinadas en un mismo referéndum), por lo que el SNP se unió a la campaña del Sí-Sí (McCrone and Lewis, 1999: 25).

\section{Control de los tiempos y cooperación: ¿euestiones clave?}

Respecto a la implicación de los partidos, la campaña para el referéndum de 1997 fue mucho más directa que la de 1979. Tres partidos cooperaron en la campaña del Sí, tanto formal como informalmente — Laborista, Liberal Demócrata y el SNP_, y en la iniciativa transversal Scotland Forward. Los tres partidos también llevaron a cabo sus propias campañas nacionales y locales y participaron en debates 
televisivos y eventos nacionales como un grupo relativamente unido. A pesar del descalabro en las elecciones generales de 1997, los conservadores participaron en la campaña del No a través de Think Twice, liderada por Brian Montieth, David McLetchie y el vicepresidente Donald Findlay, puesto que no había parlamentarios tories escoceses que quisieran estar al frente de la campaña. El laborista Tam Dalyell prosiguió en su rechazo a la devolución, pero no se adhirió a Think Twice. Comparada a la experiencia de 1979, la campaña del Sí en esta ocasión estuvo mucho más unificada y expuso un balance de 3-1 entre los partidos a favor de la devolución y los conservadores; estos últimos, una fuerza mucho menor, fuera del poder, sin fondos y conscientes de que, probablemente, el Sí obtendría una convincente victoria (Denver, Mitchell, Pattie y Bochel, 1998).

Existe otro foco de interés respecto a los referenda de devolución: el control de los tiempos fue esencial en ambas experiencias. El momento en que se llevaron a cabo influiría en si la cuestión de la devolución estaría contaminada por otros asuntos y eventos, algo que podría afectar al referéndum de independencia. En 1979, los propios diputados del Gobierno laborista forzaron el referéndum (así como el umbral del $40 \%$ ) a finales de legislatura y en un periodo de conflicto económico y político. La popularidad del Partido Laborista había caído, mientras que el SNP había decaído como fuerza política tras llegar un momento de auge, por lo que los actores de cambio estaban en pleno retroceso. En 1997, el referéndum se celebró en plena "luna de miel" del laborismo, tras una victoria aplastante en las elecciones de mayo, y tras la práctica desaparición de la representación conservadora en Escocia (Harvey y Lynch, 2012). La cuestión de la devolución se vio por tanto afectada por la popularidad del Gobierno, así como por las condiciones políticas y económicas, y, a diferencia de en 1979, el Gobierno laborista pudo elegir el momento en el que se celebraría el referéndum y cómo se haría. La larga permanencia en el Gobierno puede ser una dificultad para el SNP en el futuro: en el referéndum de 2014, ya llevaban siete años en el poder, y todavía mantenían una valoración pública razonable. En el momento de escribir (mediados de 2017), esta ha aumentado a diez años, aunque las encuestas — como se comprobó en las elecciones generales de 2017- han variado notablemente en este periodo. Un referéndum de independencia en lo que se percibe como el final de un largo periodo en el Gobierno no sería una ventaja para la causa independentista.

Por otro lado está la cuestión de las condiciones económicas y políticas en las que se celebra el referéndum. Las dificultades de esta situación se muestran particularmente claras en el referéndum de 1979. Como indicó el entonces parlamentario laborista y defensor de la devolución Dennis Canavan, sobre esa experiencia:

Había basura en las esquinas y ratas y de todo. La gente -incluso los que tradicionalmente había apoyado a Partido Laborista- se preguntaba, "¿qué demonios pasa aquí?" El país está inmerso en un caos absoluto y esperáis que vayamos a votar en un referéndum, ¿qué tiene que ver el referéndum en todo esto? Mucha gente, incluidos los votantes tradicionales del Partido Laborista, vería el referéndum como la manera de darle a Jim Callaghan y a su Gobierno un puñetazo en las narices o, incluso, un golpe mortal. (Harvey y Lynch, 2012)

Estas circunstancias no se dieron en 1997. La campaña se llevó a cabo en condiciones políticas más prometedoras y sin un bagaje económico negativo (que probablemente hubiera afectado más a los conservadores, que estuvieron en el Gobierno entre 1979 y 1997). La importancia de unas condiciones políticas y económicas positivas ha sido obvia para el SNP durante la campaña por un referéndum de independencia. En 2007, su intención fue mostrarse como un partido capaz de gobernar, ganando la confianza de la gente en el partido y, por extensión, 
en la causa independentista. También organizó una consulta durante tres años para tantear la opinión pública sobre el cambio constitucional como parte de un intento de ganar adeptos para la independencia gradualmente, con el objetivo de celebrar un referéndum en 2010. Durante este periodo, Escocia y el Reino Unido sufrieron una fuerte recesión y una serie de factores económicos negativos que podrían haber tenido efecto en el referéndum.

\section{El proceso hacia el referéndum de 2014}

En 2014, la política escocesa había cambiado de nuevo. El Parlamento escocés estaba consolidado y la clase política bien establecida. Las reglas establecidas por el Political Parties, Elections and Referendums Act 2000 habían obligado a los partidos políticos a meterse de lleno en el proceso hacia el referéndum independentista, creando y desempeñando un papel activo en grupos de campaña. La campaña a favor del Sí unió al SNP con el Partido Verde Escocés y el Partido Socialista Escocés. Better Together, la campaña a favor de la permanencia de Escocia en el Reino Unido, reunió a conservadores, laboristas y liberaldemócratas. Más allá de los partidos, otros sectores y grupos de interés, así como ciudadanos independientes, se organizaron a favor de una u otra opción. En el bando del Sí, el espectro de intereses y puntos de vista se hizo evidente de inmediato. Business for Scotland y Wealthy Nation ofrecían una perspectiva de centroderecha de la independencia, defendiendo una bajada de impuestos, libertad económica y autonomía. Esto contrastaba con la posición igualitaria de la Radical Independence Campaign. La organización Women for Independence —una de las más destacadas en el lado del Sí- se centró en cuestiones de igualdad de género y justicia social y buscaba extender la participación política de las mujeres. Generation Yes, por su parte, vio el cambio constitucional como una oportunidad para alterar el contexto político e institucional en favor de la población joven de Escocia. National Collective congregó a artistas, escritores y músicos, argumentando que "el acto creativo definitivo: crear una nueva nación" ofrecería oportunidades de cambio. La campaña escocesa por el desarme nuclear, por su lado, vio también en la independencia una oportunidad para deshacerse de las armas nucleares en Escocia. De muchas maneras, los grupos dispares mostraron las contradicciones inherentes en el corazón de la campaña a favor de la independencia; que las ambiciones y deseos de cada grupo no podrían ser cumplidas, dado que se contradecían las unas a las otras. No obstante, la naturaleza de "todo para todos" de la campaña del Sí sirvió para atraer a los votantes y abrió el debate desde su limitado enfoque en el acuerdo constitucional a una discusión más amplia y en varios frentes (Convery y Harvey, 2015).

Al contrario que en el caso español, donde la posición más absolutista del Gobierno español en relación a Cataluña —que la Constitución española prohíbe por completo un referéndum de secesión en Cataluña-, el Gobierno británico adoptó una estrategia más permisiva con respecto a las demandas de un referéndum independentista en 2014, permitiendo al Parlamento escocés organizar y celebrar la votación respetando el resultado. La relación entre el Gobierno y el Parlamento británicos de Westminster y la asamblea escocesa en Holyrood, Edimburgo, parece ser mucho más flexible que la de sus homólogos españoles. Recientemente, la posición del Gobierno británico parece haberse endurecido, a la vez que parece disminuir la posibilidad de acordar un segundo referéndum de independencia, especialmente tras las elecciones generales de junio de 2017 y el repunte de los conservadores en Escocia.

La devolución en Escocia era una reacción a una demanda clara de algún tipo de autogobierno. El establecimiento de un Parlamento escocés no fue visto 
como un peligro para la Unión, sino como un medio para asegurar su existencia. George (ahora Lord) Robertson, el secretario de Estado escocés "en la sombra", proclamó que la devolución "remataría al nacionalismo" (Harvey, 2015, p. 15). Además, la posición hegemónica del laborismo en Escocia no se veía desafiada por el SNP. Los nacionalistas no se habían involucrado en el proceso de democratización de la devolución administrativa a la ejecutiva, y no estaban en la posición —en los primeros años de la devolución- de gobernar. Sin embargo, cuando el SNP ganó el Gobierno minoritario en 2007, y subsecuentemente obtuvo la mayoría en las elecciones al Parlamento escocés de 2011, lo hicieron con la intención expresa (como se detalla abajo) de celebrar un referéndum de independencia. El Gobierno británico, guiado en parte por las encuestas de opinión, que sugerían que la opción de permanecer en el Reino Unido ganaría con holgura, retaron al SNP a declarar el referéndum. Esto era, ostensiblemente, una apuesta arriesgada: el Gobierno británico creía que su victoria sería amplia y que esta acabaría con la discusión de futuros cambios constitucionales.

Tabla 2: Comparación de los referenda en Escocia

\begin{tabular}{|c|c|c|c|}
\hline & 1979 & 1997 & 2014 \\
\hline $\begin{array}{l}\text { Propuesto } \\
\text { por }\end{array}$ & Oposición & Gobierno & $\begin{array}{l}\text { Gobiernos escocés y } \\
\text { británico }\end{array}$ \\
\hline Gobierno & Minoría laborista & $\begin{array}{l}\text { Mayoría laborista } \\
\text { holgada }\end{array}$ & $\begin{array}{l}\text { RU: coalición } \\
\text { conservadora- } \\
\text { liberaldemócrata } \\
\text { Escocia: mayoría SNP }\end{array}$ \\
\hline Cuestión(es) & $\begin{array}{l}\text { Asamblea escocesa } \\
\text { (Sí/No) }\end{array}$ & $\begin{array}{l}\text { P1. Parlamento } \\
\text { escocés (Acuerdo/ } \\
\text { Desacuerdo) } \\
\text { P2. Poderes en materia } \\
\text { fiscal (Acuerdo/ } \\
\text { Desacuerdo) }\end{array}$ & Independencia (Sí/No) \\
\hline Resultado & Sí 52-48 No & $\begin{array}{l}\text { P1. Acuerdo 74-26 } \\
\text { Desacuerdo } \\
\text { P2. Acuerdo 63-37 } \\
\text { Desacuerdo }\end{array}$ & Sí 45-55 No \\
\hline Umbral & $40 \%$ del electorado & Mayoría simple & Mayoría simple \\
\hline Conclusión & $\begin{array}{l}\text { Ley de Escocia de } \\
1978 \text { derogada }\end{array}$ & $\begin{array}{l}\text { Ley de Escocia de } \\
1998 \text { aprobada } \\
\text { Establecido el } \\
\text { Parlamento escocés en } \\
1999\end{array}$ & $\begin{array}{l}\text { Escocia permanece en } \\
\text { el RU }\end{array}$ \\
\hline $\begin{array}{l}\text { Control de } \\
\text { los tiempos }\end{array}$ & $\begin{array}{l}\text { Marzo } 1979 \text { - final del } \\
\text { "Invierno del } \\
\text { descontento" y } \\
\text { Gobierno laborista en } \\
\text { minoría }\end{array}$ & $\begin{array}{l}\text { Septiembre } 1997-4 \\
\text { meses de Gobierno de } \\
\text { Blair tras victoria } \\
\text { aplastante }\end{array}$ & $\begin{array}{l}\text { Septiembre } 2014 \text { - a } \\
\text { mediados del segundo } \\
\text { mandato del SNP en } \\
\text { Escocia; final de la } \\
\text { coalición conservadora- } \\
\text { liberaldemócrata }\end{array}$ \\
\hline $\begin{array}{l}\text { Campaña: a } \\
\text { favor }\end{array}$ & $\begin{array}{l}\text { Yes for Scotland } \\
\text { (SNP, Partido } \\
\text { Laborista Escocés } \\
\text { disidente); Labour } \\
\text { Movement Yes } \\
\text { (laborismo, sindicatos, }\end{array}$ & $\begin{array}{l}\text { Scotland Forward } \\
\text { (Partido Laborista, } \\
\text { Partido Liberal } \\
\text { Demócrata, SNP); } \\
\text { campañas individuales } \\
\text { de cada partido - }\end{array}$ & $\begin{array}{l}\text { Yes Scotland (SNP, } \\
\text { Partido Verde Escocés, } \\
\text { Partido Socialista } \\
\text { Escocés); Business for } \\
\text { Scotland; Wealthy } \\
\text { Nation; Radical }\end{array}$ \\
\hline
\end{tabular}




\begin{tabular}{|l|l|l|l|}
\hline & $\begin{array}{l}\text { Partido Cooperativo); } \\
\text { Alliance for an } \\
\text { Assembly } \\
\text { (parlamentarios } \\
\text { conservadores, } \\
\text { laboristas y } \\
\text { liberaldemócratas); } \\
\text { Conservative Yes } \\
\text { Campaign }\end{array}$ & campaña coordinada & $\begin{array}{l}\text { Independence } \\
\text { Campaign; Women for } \\
\text { Independence; } \\
\text { Generation Yes; } \\
\text { National Collective }\end{array}$ \\
\hline $\begin{array}{l}\text { Campaña: } \\
\text { en contra }\end{array}$ & $\begin{array}{l}\text { Scotland Says No } \\
\text { (conservadores, } \\
\text { empresarios); Labour } \\
\text { Vote No } \\
\text { (parlamentarios } \\
\text { laboristas anti- } \\
\text { devolución) }\end{array}$ & $\begin{array}{l}\text { Think Twice (activistas } \\
\text { del Partido } \\
\text { Conservador); } \\
\text { parlamentarios } \\
\text { laboristas individuales } \\
\text { anti-devolución }\end{array}$ & $\begin{array}{l}\text { Better Together } \\
\text { (Partidos Laborista, } \\
\text { Conservador, Liberal } \\
\text { Demócrata) }\end{array}$ \\
\hline
\end{tabular}

Como resultado, se organizó un referéndum con el apoyo del Gobierno británico —una coalición del Partido Conservador y el Partido Liberal Demócrata-, cuyas normas se establecieron en el llamado Acuerdo de Edimburgo. Entre ambos Gobiernos, se tomaron decisiones respecto al sufragio, al número de opciones y preguntas que se incluirían en la papeleta y a la fecha límite para celebrar la votación. Con una participación del $84,6 \%$, el referéndum atrajo a la población hasta niveles nunca vistos en una votación bajo sufragio universal. El primer ministro británico David Cameron tuvo varias intervenciones en el debate, enfatizando que su familia pertenecía al clan Cameron, cuyo lema "unámonos" (Let us unite, en inglés) jugó a su favor al defender la existencia de la Unión. La frase "Una Nación" fue utilizada más de una veintena de veces por el entonces líder de la oposición Ed Miliband en uno de sus discursos -ostensiblemente en el sentido económico, pero también en referencia al debate en Escocia- Tanto el ex primer ministro Gordon Brown como la actual primera ministra Theresa May hicieron sendas referencias al Reino Unido como "familia de naciones" y una "Unión de naciones", enfatizando la unidad a pesar de las diferencias de identidad (Cetrà y Harvey, 2017).

El resultado -la derrota de la propuesta independentista por 55,3\% a $44,7 \%$ - mostró a dos millones de persones a favor de permanecer en el Reino Unido frente a 1,6 millones que votaron a favor de la independencia. No obstante, las elecciones generales de mayo de 2015 reforzaron la posición del SNP respecto a la cuestión constitucional dado su bueno resultado. Mientras que en 2010 el partido había obtenido seis escaños en circunscripciones donde históricamente habían tenido un alto nivel de apoyo, en 2015 el SNP obtuvo 56 de los 59 parlamentarios en Escocia, dejando a los Partidos Laborista, Conservador y Liberal Demócrata con un escaño cada uno. Las elecciones al Parlamento escocés de 2016 devolvieron el Gobierno al SNP, aunque en minoría. Sin embargo, el aumento de escaños para el Partido Verde Escocés ha mantenido en mayoría a los parlamentarios escoceses a favor de la independencia. El Gobierno británico - tras 2015 una mayoría conservadora- buscó mermar el apoyo a la independencia extendiendo aún más la autonomía del Parlamento escocés. Las disposiciones en materia fiscal de la Ley de Escocia de 2012 fueron aprobadas tras las elecciones de 2016 y se concedieron más competencias tras el referéndum de independencia y la proceso de la Comisión Smith. Es evidente que la intención del Gobierno británico en cuanto a la cuestión constitucional es acomodar las demandas de mayor autonomía en el marco de la devolución y permitir al Parlamento escocés la oportunidad de legislar libremente dentro de sus áreas de competencia. No obstante, después del referéndum del brexit, en el que el apoyo mayoritario que 
mostró el resto de la Unión prevaleció sobre el deseo de permanencia en la UE de Escocia, la primera ministra escocesa Nicola Sturgeon indicó su intención de empezar un nuevo proceso hacia un segundo referéndum de independencia. Theresa May, por su parte, respondió declarando que "ahora no es el momento" para un segundo referéndum, insinuando que el consentimiento con dicho referéndum no se retiraría indefinidamente, pero sí en el corto plazo. En cualquier caso, el Parlamento escocés ha dado su apoyo a una orden de la Sección 30, que transferiría temporalmente el poder de celebrar un referéndum al Parlamento escocés —como hizo en 2014-, lo que significa que el Gobierno británico tendrá que tomar una decisión sobre qué estrategia planea seguir.

El argumento de Reino Unido con respecto a Escocia contiene ciertos matices. Acepta el principio de Escocia como nación, así como su derecho a la autodeterminación, aunque no sin salvedades. Esto no es algo nuevo; los ex primeros ministros conservadores Margaret Thatcher y John Major aceptaron que Escocia pudiese optar por la secesión de la Unión (Keating y McEwen, 2017: 9). En efecto, es generalmente aceptado entre los políticos británicos que se oponen a la independencia que Escocia podría ser un país independiente exitoso. Su argumento, no obstante, es que no debería querer serlo. Gran parte del argumento de los unionistas se centra en la idea del Reino Unido como una "Unión de Naciones", de "lo británico" como una identidad transversal, siendo esto complementario a la existencia de una identidad escocesa, galesa o inglesa. Tener múltiples identidades nacionales no resulta un problema para el Estado británico, que felizmente incorporara y acomoda estas actitudes si esto ayuda a conservar la Unión. Esta llamada al unionismo no es un argumento legal, sino una apelación a los lazos emocionales e históricos que unen a las naciones que componen el Estado. Este argumento señala el hecho de que no hay una barrera constitucional a la secesión y que el cambio constitucional puede llegar $-\mathrm{y}$ así ha ocurrido- para facilitar esta posibilidad.

El control de las cuestiones constitucionales continúa siendo una competencia reservada. No obstante, el Gobierno británico cedió temporalmente este control al Parlamento escocés en 2014 para permitir la celebración del referéndum de independencia. Theresa May, así como el secretario de Estado de Escocia David Mundell, han indicado que estarían dispuestos a hacerlo de nuevo en el futuro, pero que "ahora no es el momento" para tal referéndum (Johnson, 2017). En resumidas cuentas, mientas la soberanía y las competencias sobre la Constitución siguen recayendo sobre Westminster, hemos visto que esa soberanía se ha compartido en el pasado y puede compartirse de nuevo en el futuro -aunque a criterio del Gobierno central-. Este punto es importante, pues enfatiza el hecho de que la flexibilidad de la Constitución solo influye parcialmente en permitir la competencia compartida. La confianza del Reino Unido en las costumbres y los precedentes y su uso ad hoc del referéndum - generalmente, cuando se suponía a favor de los intereses del Gobierno- suponen que el compromiso del Gobierno con el derecho a la autodeterminación de las naciones que componen el Reino Unido no es una parte intrínseca de la Constitución, sino una posición a la que se ha llegado con el fin de conseguir la mayor influencia política posible. Como se ha mencionado anteriormente, la orden de la Sección 30 que otorgó temporalmente al Parlamento escocés la capacidad de convocar un referéndum fue, esencialmente, un cambio de las competencias constitucionales de la institución. Lo que también parece claro es que los actores independentistas en Escocia han estado dispuestos a participar en el proceso y a "seguir las reglas del juego" establecidas por la soberanía del Gobierno británico respecto a tal cuestión. No han amenazado con celebrar un referéndum sin el consenso del Gobierno y han estado dispuestos a negociar para conseguir tal fin, permitiendo a ambas partes mantener una postura diplomática. 
Esta experiencia llevó a Liñeira y Cetrà (2015) a establecer cuatro lecciones específicas que ser de utilidad en futuros procesos: el requisito de un mandato popular; una decisión tomada a través de un referéndum; un acuerdo entre Estado y sub-Estado para determinar los términos de la consulta; y la claridad de la pregunta en cuestión (2015: 261).

\section{El contexto cambiante}

Antes de que la devolución tomara efecto —es decir, antes de 1999- la política del SNP no era que la independencia debiera ser tratada en un referéndum; el hecho de obtener una mayoría de los escaños en Escocia en las elecciones generales (en ese momento, 37 de las 72 circunscripciones existentes) sería suficiente para poder declarar la independencia. Sí habría un referéndum para aprobar la nueva Constitución escocesa y una Carta de derechos (Scottish National Party, 1997: 6). En las primeras elecciones al nuevo Parlamento escocés en 1999, el SNP propuso celebrar un referéndum de independencia en los próximos cuatro años (Scottish National Party, 1999: 10). Esta posición cambió ligeramente en los años posteriores, con la nueva intención de celebrarlo en los últimos meses de legislatura del Gobierno. El manifiesto del SNP de 2007, de hecho, sugirió que el año sería el 2010 (Scottish National Party, 2007: 8). El manifiesto de 2011 reiteró el apoyo al referéndum independentista, aunque sin ningún compromiso de temporalidad (Scottish National Party, 2011: 28); a pesar de que la propuesta de celebrar un referéndum en la segunda mitad de la actual legislatura fue promovida antes y después de las elecciones de 2011, lo cual sería también sugerido en un anuncio del primer ministro, que establecía la celebración del referéndum en otoño de 2014.

Dado que el partido había reforzado su posición -primero en la oposición (1999-2007), después en el Gobierno escocés (2007-presente) y posteriormente (2015-presente) como el grupo más grande de parlamentarios escoceses en el Parlamento británico - el contexto y las condiciones de su éxito han cambiado. Algunos de estos cambios han sido a petición del partido y se han llevado a cabo por razones estratégicas o tácticas. El hecho de incluir un compromiso a convocar un referéndum alentó a más votantes a "ceder" su voto al partido sin arriesgarse a la independencia si ganaban una mayoría: los votantes podían votar en contra de la independencia y aun así apoyar al partido en las elecciones. Este cambio permitió al SNP enfocar su campaña en presentarse ante los votantes como una alternativa de Gobierno en las elecciones al Parlamento escocés y pedir su confianza en el manejo de la administración, dándoles a la vez la oportunidad de votar sobre la cuestión constitucional en otra ocasión.

Por tanto, aunque el apoyo al partido creció -particularmente cuando finalizó su Gobierno en minoría (2007-2011) —, el apoyo a la independencia se mantuvo razonablemente constante alrededor de un tercio del electorado. Esto cambió significativamente cuando la verdadera campaña del referéndum comenzó, pero no obstante era una indicación de la sofisticación del electorado escocés. Aunque estaban en desacuerdo con el partido respecto a la cuestión constitucional, estaban más que dispuestos a apoyarles como partido de Gobierno. Después de que la independencia fuese rechazada en el referéndum de independencia de 2014, las expectativas generales eran que volvería la "política normal", con el laborismo dominando la representación escocesa en Westminster en las elecciones generales de 2015 y volviendo al poder en Escocia en las elecciones de 2016. Esta expectativa se desvaneció cuando el SNP ganó 56 de los 59 escaños escoceses en 2015, dejando tan solo tres escaños, uno por cabeza, para laboristas, conservadores y liberaldemócratas. EI SNP no había obtenido tan solo una mayoría; había obtenido el 95 por cierto de los escaños. Veinte años antes, esto habría valido 
para declarar la independencia; pero mucho pasó en esos veinte años. Y, en efecto, la capacidad del SNP de alcanzar tal cifra de apoyos se debía, parcialmente, a la decisión de celebrar un referéndum previo a la declaración de independencia. No obstante, las circunstancias políticas - tanto constitucionales como generales- han cambiado, de nuevo, dramáticamente.

En 1951, 2,9 millones de británicos formaban parte del Partido Conservador y Unionista, mientras que el Partido Laborista contaba con 876.000 miembros. La participación fue del $83,9 \%$ y los dos grandes partidos obtuvieron el $96 \%$ de los votos y 616 de los 625 escaños de la Cámara de los Comunes. En 2011, el número de miembros de cada partido se había reducido significativamente: los conservadores contaban tan solo con 177.000 miembros mientras que el Partido Laborista, ahora la fuerza más grande, alcanzaba los 190.000. En las elecciones generales de 2010, la participación fue del $65 \%$ y, aunque entre ambos partidos aún contaban con el $87 \%$ de los votos, tan solo consiguieron 564 de los 650 escaños. Las elecciones generales de mayo de 2015 y de 2017, por su parte, supusieron un leve incremento de la participación hasta el $66 \%$ y el $69 \%$, respectivamente, aunque el apoyo combinado a los dos grandes partidos históricos ha continuado su descenso. (Convery y Harvey, 2015). Estas cifras contrastan con las presentadas en el referéndum de independencia en Escocia de septiembre de 2014, en el que el $97 \%$ de los potenciales votantes se registró para votar y la participación alcanzó el récord escocés de $84,6 \%$. Aun así, los números no hacen justicia al éxito democrático del referéndum. Los mítines en ayuntamientos estaban llenos, ciudadanos anteriormente desencantados con la política sacrificaron sus tardes y fines de semana para participar en la campaña y no se podía entrar en un bar, una tienda o un taxi sin que alguien mencionase el referéndum. Después del recuento y con la permanencia de Escocia en el Reino Unido asegurada (al menos a corto plazo), muchos de esos "reencantados" permanecieron activos y se unieron a partidos - generalmente, aquellos que habían hecho campaña a favor de la independencia-. En lo que respecta a la votación en sí, el 84,6\% del electorado 3.623.344 de los registrados- acudió a las urnas, un porcentaje significativamente mayor que la participación escocesa en las elecciones generales de 2010 (63,8 \%) y en las elecciones al Parlamento escocés (50,4\%).

En los meses posteriores al referéndum, la mayoría de los partidos vieron un aumento en el número de afiliados, prueba de que el electorado que se había comprometido con la campaña en septiembre mantenía el interés por la política y por que su voz se escuchara. El aumento en el número de miembros entre los partidos que apoyaron la independencia, no obstante, fue significativamente mayor que el de aquellos que apoyaron la permanencia. El SNP ha anunciado recientemente que su número de afiliados ha sobrepasado los 100,000 —lo que supone aproximadamente el $0,2 \%$ de la población escocesa. ¿Qué nos sugiere el hecho de que los defensores de la independencia sigan estando desproporcionadamente más involucrados en el proceso político? En parte, hay una reacción a la profecía del ex primer ministro Alex Salmond de que "el sueño nunca morirá" (Salmond, 2015), un reconocimiento si la voluntad del pueblo es el cambio constitucional, será necesario el activismo político. Por otra parte, es también un recordatorio de la voluntad de cambio, la cual se hizo evidente durante la campaña del referéndum, y del compromiso de los activistas. Pero también podemos interpretar que las bajas expectativas anteriores respecto a la política se hayan visto afectadas por la expectativa de que el cambio solo puede conseguirse mediante el activismo político a través de la militancia en los partidos. Esto sugiere que ha vuelto parte de la confianza en el sistema político; $y$, particularmente, que existe una expectativa de que el activismo político puede tener un impacto positivo (Convery y 
Harvey, 2015). La experiencia del referéndum escocés puede, por tanto, servir como catalizador de una mayor implicación ciudadana en la política.

\section{Conclusión}

A pesar de que la Constitución británica no requiere a su uso, los referenda se han vuelto más frecuentes en el Reino Unido debido a la intención de sucesivos Gobiernos británicos (y los de sus distintas regiones) de alterar los acuerdos constitucionales. Temas como la reforma electoral, la devolución, el incremento de autonomía, la independencia o la relación entre Reino Unido y Europa han sido votadas por los ciudadanos, que han estado involucrados en estos procesos de manera significativa. La participación del $84,6 \%$ en el referéndum de independencia de Escocia indicaba que la población agradece estas oportunidades de participar en procesos políticos - con la contrapartida de que esto solo ocurre cuando perciben que su participación tiene un impacto directo sobre el resultado-. La participación en 1979 y 1997 fue notable, pero no llegó hasta tal punto, mientras que la participación en las elecciones al Parlamento escocés se ha mantenido en torno al $50 \%$. En los años posteriores al referéndum de independencia, muchos de los grupos de campaña entonces establecidos han permanecido activos, mientras que muchos activistas han decidido unirse a partidos políticos. El interés en la cuestión constitucional permanece alto, aunque ni los defensores ni los detractores de la independencia parece excesivamente dispuestos a participar en otro referéndum en el futuro próximo.

La evidencia presentada en la experiencia escocesa con los referenda es clara en este sentido: el manejo de los tiempos y la manera en la que se constituyen las campañas -así como el papel del Gobierno británico en la organización de la consulta - juegan un papel relevante en el resultado. El referéndum de 1979 —con la descoordinada campaña a favor y en las últimas semanas de un debilitado Gobierno en minoría - enfatiza el lado negativo de esto. Por el contrario, el hecho de celebrar el referéndum de 1997 en el periodo inicial de la victoria aplastante de Tony Blair casi aseguró una la propia victoria del referéndum; añadiendo el factor de que los únicos detractores de la campaña, los conservadores, habían perdido todos los escaños escoceses, debilitando significativamente la campaña del No.

Para observadores interesados — potencialmente en los Gobiernos catalán y español- estas lecciones son relevantes. Para los catalanes, la participación y el acuerdo del Gobierno español es crucial para obtener legitimidad; sin ella, como hemos visto en el "proceso participativo" de 2014, el voto es meramente simbólico. Para el Gobierno español, la principal lección está en mantener el control del proceso -en particular, el manejo de los tiempos y de las reglas que rodean a la votación-, lo que ayudaría a mantener cierta ventaja sobre ellos en el que caso de que el referéndum se acabe permitiendo. Cómo se constituyen las campañas cuántos partidos establecidos participan en cada lado, y cómo se coordinan estas campañas - son también lecciones clave para ambos lados. No obstante, como hemos visto en Reino Unido en relación al referéndum del brexit, el electorado puede sorprender tanto al Gobierno como a la oposición, independientemente de los factores que estén intentando controlar.

Bibliografía

BALSOM, D. (1996), "The United Kingdom: constitutional pragmatism and the adoption of the referendum". En GALLACHER, M. y ULERI, P. V. (Eds.), The Referendum Experience in Europe, MacMillan Press Ltd., Basingstoke. 
BOCHEL, J., DENVER, D. Y MACARTNEY, A. (Eds.) (1981), The Referendum Experience: Scotland 1979, Aberdeen University Press, Aberdeen.

BOGDANOR, V. (1979), Devolution, Oxford University Press, Oxford.

BOGDANOR, V. (1994), "Western Europe". En Butler, D. y Ranney, A. (Eds.), Referendums around the world: the growing use of direct democracy. The MacMillan Press Ltd., Basingstoke.

BOGDANOR, V. (1996), Politics and the Constitution: Essays on British Government, Dartmouth Publishing Company Limited, Aldershot.

BOGDANOR, V. (1999), Devolution in the United Kingdom, Oxford University Press, Oxford..

BUTLER, D. Y RANNEY, A. (Eds.) (1994), Referendums around the world: the growing use of direct democracy, The MacMillan Press Ltd., Basingstoke.

CETRÀ, D. Y HARVEY, M. (2017), "Explaining the differing government responses to self-determination demands in Spain and the UK". Artículo preparado para la Annual Conference of the Political Studies Association, April 2017, Glasgow.

CHAMBERS, S. (2001), "Constitutional Referendums and Democratic Deliberation". En MENDELSOHN, M. y PARKIN, A. (Eds.) (2001), Referendum Democracy: Citizens, Elites and Deliberation in Referendum Campaigns, Palgrave, Basingstoke.

CONSTITUTION UNIT (1996), Report of the Commission on the Conduct of Referendums, Constitution Unit, Londres. Disponible en: http://www.ucl.ac.uk/spp/publications/unit-publications/7.pdf

CONVERY, A. Y HARVEY, M. (2015), "Political Engagement and the Scottish Referendum: Supply or Demand Explanations?". Artículo presentado en la Political Studies Association conference, March 2015, Sheffield.

DENVER, D., MITCHELL, J., PATTIE C. Y BOCHEL, H. (1998), Scotland Decides: The Devolution Issue and the Scottish Referendum, Frank Cass, Londres.

DRUCKER, H. M. Y BROWN, G. (1980), The Politics of Nationalism and Devolution, Longman, Londres.

HARVEY, M. (2015), "A tale of two countries", Scottish Left Review, March/ April.

HARVEY, M. Y LYNCH, P. (2012), "Getting to Yes: What can Scottish Independence Campaigners learn from the Devolution Referendums of 1979 and 1997". Artículo preparado para la Annual Conference of the Political Studies Association, 3-5 April 2012, Belfast.

HARVIE, C. Y JONES, P. (2000), The Road to Home Rule: Images of Scotland's Cause, Polygon, Edimburgo.

HOUSE OF LORDS SELECT COMMITTEE ON THE CONSTITUTION (2010), "Referendums in the United Kingdom", Twelfth Report of Session 2009-10, HL Paper 99, Her Majesty's Stationery Office, Londres. Disponible en: http://www.publications.parliament.uk/pa/ld200910/ldselect/ldconst/99/99.pdf

JOHNSON, S. (2017), "Theresa May tells Nicola Sturgeon 'now is not the time' for second independence referendum", The Telegraph, 16 March 2017. Disponible en: http://www.telegraph.co.uk/news/2017/03/16/theresa-may-formally-rejectsnicola-sturgeons-timetable-second/

KEATING, M. Y MCEWEN, N. (2017), "The Scottish Independence Debate". En KEATING, M. (Ed.), Debating Scotland: Issues of Independence and Union in the 2014 Referendum, Oxford, Oxford University Press, pp.152-164.

LEDUC, L. (2002), "Referendums and Elections: How do campaigns differ?". En FARRELL, D. M. y SCHMITT-BECK, R. (Eds.), Do Political Campaigns Matter? Campaign Effects in Elections and Referendums, Routledge, Londres.

LEDUC, L. (2003), The Politics of Direct Democracy: Referendums in Global Perspective, ONT: Broadview Press, Peterborough.

LIJPHART, A. (1984), Democracies: Patterns of majoritarian and consensus government in twenty-one countries, Yale University Press, New Haven. 
LIÑEIRA, R. Y CETRÀ, D. (2015). "The Independence Case in Comparative Perspective", The Political Quarterly, Vol. 86, No. 2, (April 2015), pp. 257-64.

LYNCH, P. (1996), “The Scottish Constitutional Convention 1992-5”, Scottish Affairs, No. 15 (Spring 1996), pp. 1-16.

MCCRONE, D. Y LEWIS, B. (1999), "The Scottish and Welsh Referendum Campaigns". En TAYLOR, B. y THOMSON, K. (Eds.), Scotland and Wales: Nations Again? University of Wales Press, Cardiff.

MCLEAN, B. (2005), Getting It Together: The History of the Campaign for a Scottish Assembly/ Parliament 1980-1999. Luath Press Limited, Edimburgo.

MÜLLER, W. C Y STRØM, K. (1999), Policy, Office or Votes? How Political Parties in Western Europe Make Hard Decisions, Cambridge University Press, Cambridge.

PAPADOPOULOUS, Y. (2001), "How does direct democracy matter? The impact of referendum votes on politics and policy making 2, West European Politics, Vol. 24, Part 2, pp. 35-58.

QVORTRUP, M. (2005), A Comparative Study of Referendums: Government by the People, Manchester University Press, Manchester.

SALMOND, A. (2015), The Dream Shall Never Die: 100 Days that Changed Scotland Forever, William Collins, Glasgow.

SCOTTISH CONSTITUTIONAL COMMISSION (1994), Further Steps Towards A Scheme for Scotland's Parliament, Scottish Constitutional Commission, Edimburgo.

SCOTTISH CONSTITUTIONAL CONVENTION (1995a), Key Proposals for Scotland's Parliament, Scottish Constitutional Convention, Edimburgo.

SCOTTISH CONSTITUTIONAL CONVENTION (1995b), Scotland's Parliament, Scotland's Right, Scottish Constitutional Convention, Edimburgo.

SCOTTISH NATIONAL PARTY (1997), Yes We Can win the best for Scotland: The SNP General Election Manifesto, Scottish National Party, Edimburgo.

SCOTTISH NATIONAL PARTY (1999), Scotland's Party, Scotland's Parliament: Manifesto for the 1999 elections, Scottish National Party, Edimburgo.

SCOTTISH NATIONAL PARTY (2007), Manifesto 2007: It's Time, Scottish National Party, Edimburgo.

SCOTTISH NATIONAL PARTY (2011), A Scottish Government Working for Scotland, SNP, Edimburgo.

SCOTTISH OFFICE (1997), Scotland's Parliament, (Cmnd. 3658), Her Majesty's Stationery Office, Londres. Disponible en: http://www.scotland.gov.uk/government/devolution/scpa-00.asp

SETÄLA, M. (2006), "On the Problems of Responsibility and Accountability in Referendums", European Journal of Political Research Vol. 45, Issue 4, June 2006, pp. 699-721.

SMITH, J. (1998 [1981]), "Interview: Portrait of a Devolutionist". En PATERSON, L., A Diverse Assembly: The Debate on a Scottish Parliament, Edinburgh University Press, Edimburgo.

TIERNEY, S. (2012), Constitutional Referendums: The Theory and Practice of Republican Deliberation, Oxford University Press, Oxford.

WRIGHT, K. (1997), The People Say Yes: The Making of Scotland's Parliament, Argyll Publishing, Argyll. 